instrumentation side, certain techniques, such as gel electrophoresis, which are central to the new methods of molecular biology, may be singled out for increased attention; but Philipson is also said to have shown his support for the great efforts being made at Heidelberg to improve electron microscopy through cooling the microscope and specimen (see accompanying box).

At present Sir John Kendrew is still firmly in charge. He foresees an increase in the number of permanent scientific appointments (still less than a handful) at the laboratory in the next couple of years, as a batch of the early short-term contracts come to an end. Philipson, however, has made no commitments. As for Sir John himself, he feels that the seven years and three months for which he will have held the directorship is quite long enough.

Robert Walgate

\section{Polish crisis}

\section{Science in limbo}

The "state of war" proclaimed by General Jaruzelski's "Military Council for National Salvation" has brought all academic life in Poland to a standstill. The universities are closed as are several institutes of the academy of sciences. Scores of scientists and scholars have been arrested although some, such as the president of the academy, Dr Aleksander Gieyszter, have since been released. Others escaped arrest only by chance, being away from home when the police came, and are now in hiding. Solidarity organizers in the learned professions and activists from the Independent Students' Association have been interned. The Minister of Science, Higher Education and Technology, Dr Jerzy Nawrocki, is reported to have resigned.

This clamp-down on intellectuals is in sharp contrast with Jaruzelski's previous attitude. In a recent interview, Dr Leonard Sesnewski, one of the vice-presidents of the academy, said that Jaruzelski had always expressed warm feelings for scientists and that, on taking of fice as prime minister last February, he had immediately visited the academy to ask for their help in getting Poland out of its economic crisis.

Nevertheless, the growing drive for academic autonomy must have caused a certain friction between the general and the academy. At present, the academic secretary of the academy holds quasiministerial rank, and is responsible to the prime minister. In recent months, however, there has been considerable pressure from academy members and employees to incorporate into the proposed new bill on the academy clauses that would terminate this structure and make the academic secretary responsible only to his fellow-academicians. There has also been a drive - reflected in the Solidarity Congress resolution on learning and culture - to break down the barriers between the universities and the academy, so that academy employees could deliver lectures to undergraduates. This trend may have seemed dangerous to the authorities; a number of scholars, expelled or excluded from teaching posts for their political views over the past few years, have found a safe haven in academy research posts insulated from teaching.

For the time being, the concern of scholars abroad is focused on the plight of their Polish colleagues interned or in hiding. Professor Olof Tandberg and his colleagues from the Swedish Academy of Sciences (which traditionally has strong links with Poland) and several members of the Norwegian Academy have launched an appeal for financial support for the families of interned academics. Professor Tandberg has also received an appeal from a group of academy scholars in hiding asking for food, blankets and other essential supplies, including blood plasma. $\mathrm{He}$ has called on all other academies throughout the world to join the Norwegian and Swedish academics in this work.

Vera Rich

\section{UK agricultural research Endangered duo}

Two British agricultural research institutes, the Long Ashton Research Station in Bristol and the Animal Breeding Research Organisation in Edinburgh, could be drastically cut or even closed if an economy proposal by the Agricultural Research Council is approved at its next meeting in February. Under threat are all research programmes at the Edinburgh institute except work on fundamental animal genetics, and the Pomology and Food and Beverages Division at Long Ashton.

The council (ARC) hopes the closures will save about $£ 3$ million in annual expenditure by 1983-84. (The budget for 1981-82 is £86 million.) According to $\mathrm{Dr}$ Ralph Riley, the secretary of ARC, the savings are needed both as a hedge against future government cuts and to allow greater flexibility in supporting research of high priority. The council's research programme has already suffered, he says, from a budget that has not kept up with inflation. Non-payroll expenditure has already been pared to the bone. But precisely how much of the $£ 3$ million saved will be available for starting new research projects after cuts in income are taken into account remains uncertain.

If the proposal is approved, the Long Ashton Research Station will be reduced to about one half of its present strength, with the loss of about 100 jobs. The Animal Breeding Research Organisation, however, will probably be closed and the research on animal genetics, which accounts for about one-fifth of the organization's activity, moved elsewhere.

ARC has made the proposal without consulting the staff or directors of the institutes concerned, who first learnt of it only last week. The idea, according to Dr Riley, was for ARC to propose firm suggestions for savings and then to give those concerned two months in which to make a case before a final decision. The way in which the proposal was arrived at remains something of a mystery, but the main criterion seems to have been an assessment of priorities based on recent reviews of the work of all the council's institutes. Areas in which the council is likely to want to spend more money include fundamental genetics and biotechnology.

If approved, the proposal could have implications for the Ministry of Agriculture, Fisheries and Food, which spends about $£ 44$ million a year in ARC institutes on commissioned research. The ministry is optimistic that the work it commissions in the institutes under threat could be transferred to other institutes. Dr Riley, however, believes that this will be possible for most commissioned research but that there may be some areas where the ministry will have to look elsewhere. Judy Redfearn

\section{High-energy physics \\ LEP marches on}

The large electron-positron ring is on the move - in more than one sense. LEP will be the next big accelerator at CERN, the European Centre for Nuclear Physics, Geneva, and last week CERN member states finally agreed on the budget under which it will be built. Thus construction can begin as soon as local environmental approval is granted - by January or February, it is hoped. The second move is physical: LEP is to be built in a significantly new position, on a slope, which allows it to slide out of some tricky geological and political problems.

The budget agreed is sufficient, says CERN director-general Professor Herwig Schopper, to build LEP on the schedule foreseen a few months ago: fast enough to give colliding electron and positron beams of sufficiently high energy to provide physicists with copious neutral intermediate vector bosons by the end of 1987 .

LEP is expected to cost SF910 million (about $£ 263$ million) at 1981 prices, with a further SF40 million (making a total of $£ 275$ million) for the first experiments. The money will be drawn from a guaranteed CERN annual budget of SF617 million.

The only major argument at the council was over what inflation index to apply to the 1981 budget to scale it up to 1982 prices. The usual CERN formula, appropriately weighted for CERN's Swiss salaries and expenditure abroad, gave 5.7 per cent. The council quibbled, and agreed on 4.4 per cent, losing CERN over $£ 2$ million next year.

The new slope for LEP (it was to have been horizontal) will be about 1.5 per cent from the Jura Mountains in the north west, towards Geneva. This enables the machine 